\title{
PEDIATRIC NEUROLOGY BRIEFS
}

A MONTHLY JOURNAL REVIEW

\author{
J. GORDON MILLICHAP, M.D., F.R.C.P., EDITOR
}

Vol. 2, No. 10

October 1988

\section{SEIZURE DISORDERS}

\section{SEIZURES AND VENTRICULAR SHUNTS}

The role of ventricular shunts as a cause of seizures in children with hydrocephalus was studied in 190 patients treated for myelomeningoele in the Dept of Neurosurgery, Arkansas Children's Hospital, Little Rock, AR. The period of follow-up was 1-26 yrs, with an average of 9 yrs. The frequency of seizures in 144 shunted compared to 46 nonshunted patients was $22 \%$ and $2 \%$, respectively. If modification of the shunt was unnecessary, only $9 \%$ had seizures, whereas in those requiring modification the incidence was $22 \%$. A shunt infection raised the risk of seizures to $47 \%$. Seizure frequency was approximately the same in those with frontal or parietal location catheters, 20 and $26 \%$, respectively. of 7 patients with unorthodox locations of shunt placements, near the motor cortex, 4(57\%) developed seizures. (Chadduck W, Adametz J. Incidence of seizures in patients with myelomeningocele: a

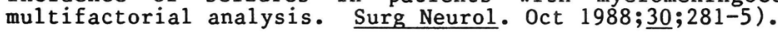

COMMENT. One in four infants with myelomeningocele who are shunted for hydrocephalus develop seizures. Cortical injury at the time of shunt placement is a likely factor in etiology, and a complicating bacterial infection, even lowgrade in type, will lead to diffuse cerebral injury and will double the risk of seizures. Candida meningitis has been reported in patients with CSF shunts (Surgarman B. Arch Neurol $1980 ; 37 ; 180)$, and a single colony of yeast should $\frac{\text { not }}{\text { not }}$ be considered a contaminant especially in infants with hydrocephalus, ventricular shunts and cranial nerve palsies (Coker SB, Beltran RS. Candida meningitis; Clinical and radiographic diagnosis. Pediatr Neurol 1988; $4: 317$ ). McLone

PEDIATRIC NEUROLOGY BRIEFS 1988 covers selected articles from the world literature and is published monthly. Subscription requests ( $\$ 28$ US or L15 UK annually; add $\$ 5$ (L3) for airmail outside North America) may be sent to: Pediatric Neurology Briefs - J. Gordon Millichap, MD, FRCP - Editor, P. O. Box 11391, Chicago, IL 60611, USA, or P. 0. Box 1605, London w8 7JD, UK. The Editor, Professor of Neurology and Pediatrics at Northwestern University Medical School, Chicago, is presently at SIU School of Medicine, Springfield, Illinois, USA. 
et al (Pediatrics 1982;70:338) have alluded to the effect of CNS infections on the intelligence of children with myelomeningocele, and the occurrence of seizures is a further complication of surgery. Delay in operative closure of the spina bifida may reduce the severity of hydrocephalus and lessen the need for shunting with its attendant risks (see ped Neur Briefs $1988 ; 2: 52$ ).

MATERNAL EPILEPSY AND CHILD'S IQ.

The intelligence of 116 children of epileptic mothers enrolled in a prospective study during pregnancy was compared with that of 104 control children at the Univ of Helsinki and Children's Castle Hospital, Helsinki, Finland. The prevalence of mental deficiency was $1.4 \%$ in the study group and zero in controls. Mean IQ's at $51 / 2$ yr examinations were significantly lower in the study group compared to controls but showed no relation to exposure to antiepileptic drugs or to brief maternal convulsions. Among phenytoin-exposed children, 1 of $103(1 \%)$ was mentally retarded and 1 had borderline IQ, short stature, microcephaly, and 8 minor anomalies. Multiple minor anomalies were associated with a lower mean IQ in both study and control groups. Hypertelorism and digital hypoplasia, typical of the fetal hydantoin syndrome, did not predict a poor intellect. (Gaily $E$ et al. Intelligence of children of epileptic mothers. $\mathrm{J}$ Pediat Oct $1988 ; 113 ; 677-684)$.

COMMENT. This study shows a slight increase in prevalence of mental deficiency among children of epileptic mothers compared with the general population. Exposure to nontoxic levels of phenytoin as monotherapy or in combination with one other antiepileptic drug did not impair IQ. These reults are contrary to those of Hanson et al ( $J$ Pediat $1976 ; 89 ; 662$ ) who found that intrauterine exposure to phenytoin was a major risk factor for mental subnormality in affected children).

PHENOBARBITAL AND VALPROATE FOR FEBRILE CONVULSIONS

Data from 6 British trials of phenobarbital and 4 trials of valproate for the prophylactic treatment of febrile convulsions were polled and analyzed on an intention to treat basis at the Dept of Neurology, Royal Manchester and Booth Hall Children's Hospitals, Manchester. The risk of recurrence in the treatment groups compared to controls expressed as an overall odds ratio was as follows: for phenobarbital, 66 of $296(22 \%)$ of treated children had recurrence compared to 58 of $236(25 \%)$ of controls (overall odds ratio or relative risk of 0.8 , nonsignificant difference); for valproate, 49 of $145(34 \%)$ treated children had recurrence compared with 36 of $136(25 \%)$ controls (overall odds ratio of 1.42 , nonsignificant result). The follow-up period ranged from 6 months to a mean of 30 months. An odds ratio of less than 1 suggests benefit; greater than 1 suggests no benefit from treatment. (Newton RW. Randomized controlled trials of phenobarbitone and valproate in febrile convulsions. Arch Dis Child Oct $1988 ; \underline{63}: 1189-91)$. 